\title{
Endoscopic ultrasound-guided therapy of a gastro- intestinal stromal tumor (GIST)
}

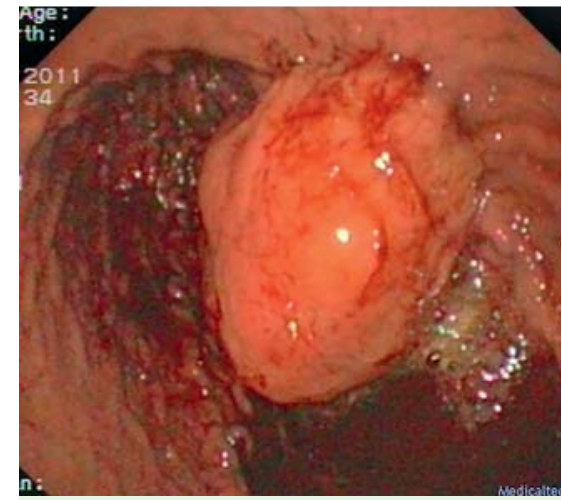

Fig. 1 Subepithelial lesion in a 90-year-old man undergoing endoscopic ultrasound-guided sclerotherapy for recurrent upper gastrointestinal bleeding shows no stigmata of bleeding.
A 90-year-old man was admitted to our hospital because of recurrent upper gastrointestinal bleeding due to a 5 -cm gastrointestinal stromal tumor (GIST) in the lesser curve of the stomach ( $\bullet$ Fig. 1). After conventional endoscopic sclerotherapy failed to achieve a response, and because of the patient's condition, it was decided to perform endoscopic ultrasound (EUS)-guided therapy.

The lesion was located at the lesser curve of the stomach; therefore, it was easily approached with the echoendoscope and punctured with a 20-gauge needle (Cook Ireland Ltd., Limerick, Ireland). This needle is specifically designed for celiac plexus neurolysis, and the multiple per-

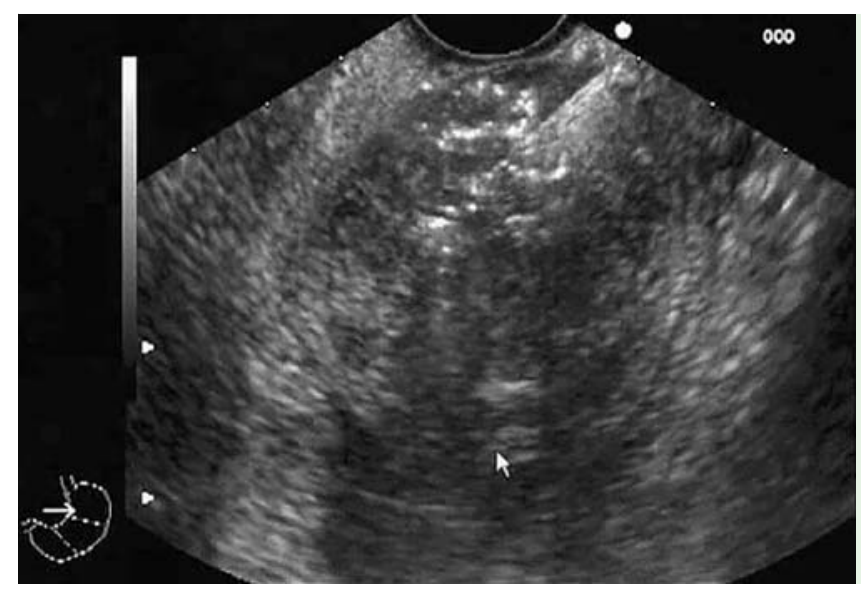

Fig. 2 Endoscopic ultrasound-guided sclerotherapy with the injection of alcohol into the middle of the lesion (arrow).

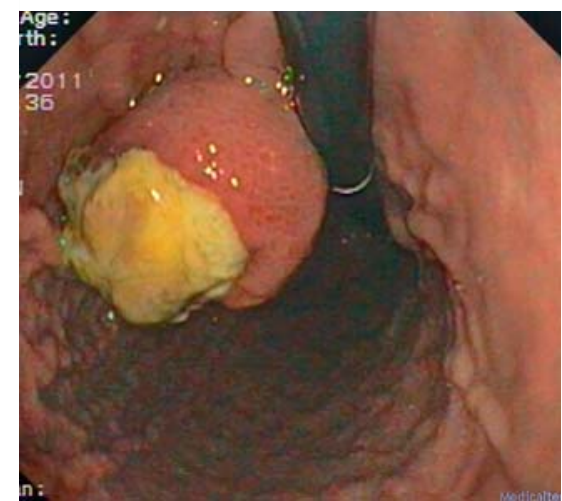

Fig. 3 Partial necrosis of the lesion at 1 week after treatment.

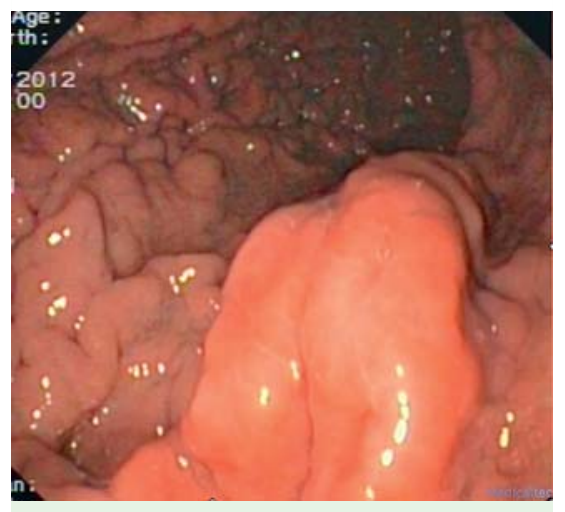

Fig.4 Disappearance of the treated lesion after 3 months. forations at the tip allow better diffusion of the injected agent. The needle was placed in the middle of the lesion, and $1.5 \mathrm{~mL}$ of $99 \%$ alcohol was injected ( $\bullet$ Fig.2). The original plan had been to inject the alcohol first in the middle of the lesion and then in the distal and proximal areas to ensure adequate therapeutic coverage. However, because excellent diffusion of the alcohol was observed along the entire lesion during the first injection, it was not placed in other areas.

During a second-look endoscopy 1 week later, partial necrosis of the lesion was noted $($ Fig. 3 ), and 3 months later, the tumor had practically disappeared ( $\bullet$ Fig. 4). Only a slight, isolated thickening of the gastric folds was seen. During a follow-up of 3 years, no episodes of rebleeding occurred.

Although the first-line treatment of GISTs is surgery, EUS-guided therapy can be considered because it has been demonstrated to be feasible and effective in selected cases. Complications resulting from the injection of alcohol in luminal and extraluminal gastrointestinal lesions, such as ulcerations in gastric lesions [1] and intratumoral hemorrhage and pancreatitis in hepatic and pancreatic lesions, have been described [2-5]. However, all reported cases were mild and responded to conservative therapy.

Endoscopy_UCTN_Code_TTT_1AS_2AB

\section{Competing interests: None}

\section{Eduardo Valdivielso Cortázar, Ignacio Fernández-Urién, Juan José Vila Costas, Francisco Javier Jiménez Pérez}

Digestive Department, Complejo Hospitalario de Navarra, Pamplona, Spain

\section{References}

1 Günter E, Lingenfelser T, Eitelbach $F$ et al. EUS-guided ethanol injection for treatment of a GI stromal tumor. Gastrointest Endosc 2003; 57: $113-115$

2 Barclay RL, Pérez-Miranda M, Giovanninni M. EUS-guided treatment of a solid hepatic metastasis. Gastrointest Endosc 2002; 55 : $266-270$

$3 \mathrm{Hu} Y$ Y , Tuo XP, Jin ZD et al. Endoscopic ultrasound (EUS)-guided ethanol injection in hepatic metastatic carcinoma: a case report. 
Endoscopy 2010; 42 (Suppl. 02): E256E257

4 Jürgensen C, Schuppan D, Neser $F$ et al. EUSguided alcohol ablation of an insulinoma. Gastrointest Endosc 2006; 63: 1059-1062

5 DeWitt J, McGreevy K, Schmidt CM et al. EUSguided ethanol versus saline solution lavage for pancreatic cysts: a randomized, doubleblind study. Gastrointest Endosc 2009; 70 : $710-723$
Bibliography

DOI http://dx.doi.org/

10.1055/s-0034-1391952

Endoscopy 2015; 47: E262-E263

(c) Georg Thieme Verlag KG

Stuttgart · New York

ISSN 0013-726X
Corresponding author

Eduardo Valdivielso Cortázar, MD

Gastroenterology Department

Complejo Hospitalario de Navarra

Calle Irunlarrea 3

31008 Pamplona

Navarra

Spain

Fax: +34-619-39-00-52

eduardovaldi@hotmail.com 